\section{Editorial: All Aboard for a Game of Educopoly}

Hugo MANSON

A $t$ the end of 1993, education in New Zealand was in a state of quiet confusion as it negotiated its way through the stalls of the marketplace into which it has been thrust, with its customers (students), its business associates (experts in public relations and packaging) and its wares (measurable outcomes). It's now all aboard for the game of Educopoly, with many still not sure of the rules. Some even felt they weren't included and could not make it past "Go". For Educopoly, like all market games, is competitive, and not to be a winner is to be a loser, or at least, to be condemned to pay rent on others' property and to rely for sustenance on an ever diminishing Community Chest.

Government policy pursued its path perceived (by the Government) as the highroad to the outcome of more, better educated New Zealanders (though there was relatively little public discussion of the nature of the knowledge we think desirable, but rather an emphasis on the acquisition of internationally recognised and saleable skills).

And we had an election at which New Zealanders expressed a resounding lack of trust in politicians of both major parties (and what they had done to our education system?)

In the new market environment of Educopoly, a number of alarming manifestations began to become commonplace, no longer remarkable. Among them, the glossy advertisements of educational institutions (private and state) designed to attract clients (students), creating the growing spectre of the "good"
4 Hugo Manson

schools as opposed to the "others". In such come-on advertising, money began to speak. Elitism (so easily created, self-perpetuated and so difficult to eradicate) was seen to re-germinate, to the continuing disadvantage of those with not enough dollars to see them through the game, those with skin of a different colour from the winning (usually white, middle class) players and even those of the female gender (see, for example, the articles by Kathie Irwin, Anne Marie O'Neill and Marion Court in this issue). Money continued to speak by dividing New Zealand would-be university students into "pass-Gos" and "do-not-pass-Gos" through the raising of fees to unprecedented levels.

The elections said it nationally; the student demonstrations said it locally - there was a lack of trust in what was happening in the country and in education.

The notion of trust in educational policy making is worth consideration. Patricia White, in her succinct characterisation of the democratic state, underlines the place of trust and the place of distrust in the institutions of a political system which wants to promote the wellbeing of all its citizens. Trust, she says, "involves the belief that you can rely on someone (e.g., specifically, their beliefs, dispositions, motives, good will) or something (e.g., the efficiency of a piece of equipment) where there is a greater or lesser element of risk... (it is) a necessary condition for social trust that citizens do not regard their society as structurally unfair" (White, 1991, p 12-13). Such a belief has been clearly absent among many New Zealanders' feelings about developments in their education system. On the other hand, White emphasises that distrust, in the form of protective devices, such as a legal opposition and an independent judiciary, a free press and so on, should be built into the system to question and keep an eye on its fundamental aims, means and procedures. The balance between trust and distrust, as White defines them, is a delicate but important one.

In the context of New Zealand educational developments in the last few years, the conflagration of confusion resulting from 
the many changes has led to an absence of trust, but also, ironically, to an inability to apply fully the mechanisms of legitimate distrust (in White's terms). The application of such mechanisms of distrust has been made particularly difficult by the shifting of public education to the marketplace. Whatever else might be said of this shift, two results stand out. Firstly, involvement in the marketplace seems to require the adoption of a competitive mentality, and competition requires tactics, manoeuverings - and secrecy. Secondly, there was a compliance (if protesting), to the market shift from the education sector. This compliance was the result of a number of factors, for example the confusion resulting from the speed and magnitude of the changes under the former Labour government; the ignorance of teachers, parents, governors and councils of the implications of the changes; the glossy sell of many of the changes; the skilful use of alarming language (e.g.," professional/union capture") during the "sale" of the proposals. For these and other reasons such as the relative weakness of some professional organisations, the compliance to the shift of education to the marketplace was understandable, if not justifiable. It is surprising and alarming, however, that New Zealand universities, for instance, did not take a stronger stand and refuse to follow government policy (if they disagreed with it). Instead, they have slotted into the market structure playing their full part as competitive marketeers, accepting the unacceptable (e.g., high student fees) and selling their wares. Like the best of salespeople they display their campuses in expensively produced brochures. The vice chancellor of one university was even reported as exhorting his staff to avoid critical comment about their university for fear of putting off potential students - so much for universities as vibrant, selfcritical institutions of learning.

Most alarming of all, though, and most stifling of legitimate mechanisms of institutional distrust is the competitive market requirement of secrecy of many decision making procedures. Participants in the marketplace don't reveal their game. In practice, this means that matters considered by each competitor to be commercially sensitive (and how many matters are unjustifiably sheltered behind that rubric in New Zealand state educational institutions?), are not discussed in public. Therefore a situation exists where the process of decision making of these institutions, in its most commercially sensitive parts, is invisible to the owners, the people. This is a concealment that makes the legitimate mechanism of distrust, i.e., the bona fide monitoring of processes, agendas and resources impossible, or at least very difficult. The implications of this for academic freedom and independence are dire. For, from the processes of administrative and financial decision making come the essential structures surrounding and controlling any institution. Whether one agrees or not with government policy, it is essential, in a democracy, for the citizen to be able to see with all the clarity desired, the effect of that policy on the ways the institution comes to its decisions.

The confusions of 1993, fuelled by this fundamental area of market/competition imposed ignorance, spilled into the area of curricular reform. Warwick Elley, in this issue, questions what he calls "needless assessment requirements" cutting across desirable aims of the Curriculum Framework. Bob Stephens highlights the fundamental and unresolved question of who should pay for education, a matter which requires full public disclosure of all details of spending in educational institutions. And, at the other end of the spectrum, there was the ultimate confusion as to what education is all about nurtured by those students who were suspended from their schools in their thousands in 1993 alone. (See the article by Cathy Casey).

If the picture at the end of 1993 seemed quietly confused in New Zealand education, it was because of the uncertainty fuelled by the exigencies of the competitive marketplace in which the education sector now finds itself. The players in the game of Educopoly are finding the competitive life tough. It is particularly hard for those who are not winning when they can't check that everyone is playing by the rules. 


\section{Reference}

White, Patricia "Humanisation, Democracy and Trust: The Democratisation of the School Ethos", in Studies in Philosophy and Education 11, The Netherlands: Kluwer Academic Publishers, 1991.

\section{The editor}

Hugo Manson is writing a PhD thesis on political education at Victoria University of Wellington. He is co-founder and manager of the Oral History Centre at the Alexander Turnbull Library, and has been a broadcaster for many years. 